\title{
MECANISMOS DE CONVOCAÇÃO PELA IMAGEM NAS CAPAS DE REALIDADE: JUSTAPOSIÇÃO E A ARTICULAÇÃO DE UM NOVO LUGAR DE CONSUMIDOR NA NARRATIVA
}

\author{
Image convocation mechanisms in the cover of Realidade magazine: \\ justapositions and the jointing of a new consumer place in the narrative
}

\author{
Mecanismos de convocación por la imagen en las capas de Realidade: \\ justaposición y la articulación de un nuevo lugar del consumidor en la narrativa
}

Eliza Bachega Casadei

Professora titular do Programa de Pós-graduação em Comunicação e Práticas do Consumo da Escola Superior de Propaganda e Marketing de São Paulo elizacasadei@yahoo.com.br

\section{Resumo}

A partir de um estudo que mapeia as estratégias de composição de imagem de revistas brasileiras ao longo do século XX, o objetivo do presente artigo é expor alguns dos dispositivos de convocação para o consumo nas capas da revista Realidade, em contraste com aqueles utilizados pelas principais publicações brasileiras do período anterior, como Revista da Semana e $O$ Cruzeiro. A justaposição, na revista Realidade, se estrutura como a principal estratégia composicional utilizada na maior parte das capas. Isso implica na articulação de um mecanismo de convocação que constrói um novo lugar para o leitor na imagem: ao invés de imaginá-lo como uma entidade que projeta suas fantasias aspiracionais em figuras exemplares, como no período anterior, Realidade convoca-o a partir de um convite para o deciframento de um sentido conotado, explicitando os processos de feitura da imagem e sua arbitrariedade sígnica.

Palavras-chave: Fotojornalismo. Capas. Convocação. Composição Imagética. Justaposição.

\begin{abstract}
From a study that maps image composition strategies in Brazilian magazines throughout the twentieth century, the objective of this article is to expose some of the convocation mechanism for consumption in the covers of Realidade magazine, in contrast to those used by the main Brazilian publications of the previous period, such as Revista da Semana and $O$ Cruzeiro. Juxtaposition, in Realidade magazine, is structured as the main compositional strategy used in most of the covers. This implies in the articulation of a convocation mechanism that constructs a new place for the reader in the image: instead of imagining it as an entity that projects its aspirational fantasies into exemplary figures, as in the previous period, Realidade convoke it from an invitation to the decipherment of a connoted sense, explaining the processes of implied in the image making and its signic arbitrariness.
\end{abstract}


Key words: Photojournalism. Covers. Convocation. Imaging Composition. Juxtaposition.

\section{Resumen}

A partir de un estudio que mapea las estrategias de composición de imagen en revistas brasileñas a lo largo del siglo XX, el objetivo del presente artículo es exponer algunos de los dispositivos de convocación para el consumo en las portadas de la revista Realidade, en contraste con aquellos utilizados por las principales publicaciones brasileñas del período anterior, como a Revista da Semana y O Cruzeiro. La yuxtaposición, en la revista Realidade, se estructura como la principal estrategia compositiva utilizada en la mayor parte de las capas. Esto implica en la articulación de un mecanismo de convocación que construye un nuevo lugar para el lector en la imagen: en vez de imaginarlo como una entidad que proyecta sus fantasías aspiracionales en figuras ejemplares, como en el período anterior, Realidade lo convoca a partir de una invitación para el desciframiento de un sentido connotado, explicitando los procesos de elaboración de la imagen y su arbitrariedad sígnica.

Palabras clave: Fotoperiodismo. Portadas. Convocaciones. Composición imaginaria. Justaposición.

\section{INTRODUÇÃO}

Ao colocar a pergunta “O que as imagens realmente querem?", Mitchell (2015) desloca a perspectiva a partir da qual elas são normalmente interrogadas. Posto que a ênfase dada pelas correntes teóricas vinculadas às questões interpretativas, retóricas e hermenêuticas está no desvendamento do desejo do produtor ou no entendimento de que a imagem é um mecanismo que suscita desejos no espectador, Mitchell propõe inverter a perspectiva e olhar a própria imagem como um dispositivo desejante. E, ora, a quem deseja, sempre falta algo. O que falta então à imagem? A resposta dada por Mitchell a essa pergunta é categórica: à imagem falta poder.

Para chegar a tal conclusão, Mitchell faz uma crítica a abordagens teóricas que expõem a imagem como um agente poderoso de manipulação ideológica. "Certamente, as imagens não são desprovidas de poder, mas podem ser muito mais frágeis do que supomos" (MITCHELL, 2015, p. 171). Para isso, a persona que ele dota a imagem desejante não é aquela vinculada à figura do dominador, do hegemônico ou do prevalente. A persona da imagem desejante estaria mais próxima das figuras subalternas ou das minorias, no sentido de corporificações que lutam (e desejam) por um poder que não têm. As imagens, "acima de tudo, gostariam de exercer alguma maestria (maistrye) sobre o espectador”. Em outros termos, "Fried resume a 'convenção primordial' da pintura nos seguintes termos: 'uma pintura deve, 
primeiramente, atrair o espectador, depois prender seu olhar e finalmente encantá-lo" (MITCHELL, 2015, p. 173).

As imagens, para o autor, portanto, desejam um poder que é manifestado como falta e não como possessão. Seu poder persuasivo se estrutura mais como desejo do que como efetividade (o que explica porque certas imagens propagandísticas não possuem eficácia alguma). A despeito de seu desejo persuasivo, tal vontade nada diz sobre seu poder real, de forma que a única coisa que podemos inferir sobre as imagens é a construção desse desejo em relação a fantasias de poder.

A imagem é um dispositivo afônico, uma vez que, "para ser claro, as fotografias não dizem nada (...) permanecem mudas". No entanto, “qualificá-las de 'silenciosas' seria talvez mais apropriado na medida em que esse epíteto designa um estado (o silêncio) mais do que uma ausência" (MARESCA, 2012, p. 37). Isso significa dizer que a quietude das imagens se dá não necessariamente pela ausência de voz, mas sim, porque essa voz é sempre delegada a outrem, que diz o que a imagem supostamente quereria dizer. Assim, para Mitchell, "acima de tudo", portanto, a imagem "quer ser escutada" (MITCHELL, 2015, p. 184). Marcada pelos pressupostos que regem certos aspectos da inteligibilidade ocidental, a imagem se apresenta como um cadáver mudo exposto a um olhar de deciframento (CERTEAU, 2008). Assim como o subalterno, que não pode falar por si só posto que está desprovido de um lugar legitimado de fala, a imagem também está dentro desse campo de inteligibilidade que marca o lugar de saber como um saber sobre o outro - e, mais do que isso, um saber a respeito daquilo que o outro cala. Trata-se de uma heterologia "(discursos sobre o outro) que se constituíram em função da separação entre o saber que contém o discurso e o corpo mudo que o sustenta" (CERTEAU, 2008, p. 15). A imagem, afinal, "deseja uma alteridade” (NANCY, 2015, p. 60). É por isso que, para Mitchell (2015, p. 185), é importante “considerar as imagens não como sujeitos soberanos ou espíritos desencarnados, mas como subalternos cujos corpos são marcados pelos estigmas da diferença, que funcionam tanto como mediuns quanto como bodes expiatórios no campo social da visualidade humana".

Se aceitarmos as considerações de Mitchell sobre as articulações da imagem como um dispositivo desejante e aplicarmos tais reflexões para o estudo das capas de revista brasileiras, é possível considerar que, embora desde sempre elas tenham se articulado em torno do desejo de poder de convencimento, as estratégias convocacionais urdidas para essa finalidade variaram consideravelmente ao longo do tempo. O final da década de 1960 é um período especialmente interessante, nesse sentido, uma vez que, nessa época, surgiram uma série de 
revistas (como Realidade e Veja, por exemplo) que apostaram em estratégias de convocação para o consumo a partir da imagem bastante diferentes daquelas utilizadas no período anterior. A aposta afetiva-editorial implicada na estruturação dessas capas era distinta daquelas descritas nos períodos anteriores, especialmente em Revista da Semana, O Cruzeiro ou Manchete.

O objetivo do presente artigo é, justamente, mapear alguns dos dispositivos de convocação para o consumo nas capas da revista Realidade, em contraste com aqueles utilizados pelas principais publicações brasileiras do período anterior. Ao analisarmos a revista Realidade podemos adotar a mesma pergunta feita por Mitchell: o que desejavam as capas da revista Realidade? Isso implica em observá-las a partir de sua perspectiva desejante e, principalmente, a partir de como é articulado, na composição, os seus mecanismos convocacionais. Nesse sentido, mapearemos as estratégias de construção de sentido de suas capas a partir da esquematização das estratégias convocacionais urdidas.

Na revista Realidade, como esmiuçaremos a seguir, a justaposição é a principal estratégia composicional utilizada na maior parte das capas. Isso implica na estruturação de um mecanismo de convocação que constrói um novo lugar para o leitor na imagem: ao invés de imaginá-lo como uma entidade que projeta suas fantasias aspiracionais em figuras exemplares, como no período anterior, Realidade convoca-o a partir de um convite para o deciframento de um sentido conotado, explicitando os processos de feitura da imagem e sua arbitrariedade sígnica. Além disso, é possível notar que a justaposição, do ponto de vista temático, não é aleatória, mas atende a certos imaginários sobre como o jornalismo deve se estruturar, emergentes a partir da década de 1960 no cenário brasileiro ${ }^{1}$.

\section{SOBRE AS ESTRATÉGIAS CONVOCACIONAIS DE CAPA: DO APELO AO STAR SYSTEM À ARTICULAÇÃO DO SOCIAL COMO PERSONAGEM}

As modificações na linguagem imagética presentes na revista Realidade (e as consequências que isso acarretou em termos de convocações para o consumo) já haviam sido preparadas pelos padrões fotográficos adotados pela Revista da Semana e por O Cruzeiro no período anterior. Trata-se, portanto, de um processo que já estava em curso e que está relacionado aos momentos de profissionalização do fotojornalismo no país. Desde o final da

\footnotetext{
${ }^{1} \mathrm{O}$ presente artigo parte de uma pesquisa mais ampla que estuda os mecanismos de convocação pela imagem nas revistas brasileiras ao longo do século XX, com apoio do edital CNPQ/ MCTI No 25/2015 - Ciências Humanas, Sociais e Sociais Aplicadas.
} 
década de 1940, por exemplo, as revistas já haviam abandonado "velhos clichês que preconizavam o uso da fotografia como mero recurso de ilustração" (MAGALHÃES, PEREGRINO, 2004, p. 54).

$\mathrm{Na}$ historiografia sobre o tema, é notória a ênfase dada ao maior caráter autoral dado às fotografias, de forma que eram frequentes imagens com carga grande subjetiva (tanto do ponto de vista temático quanto na perspectiva estética). A periodicidade da publicação, que era mensal, também é apontada como um fator relevante para a obtenção de uma maior profundidade nas coberturas fotográficas (LEITE, 2015). Para Leite (2015), é possível posicionar a revista Realidade em um entremeio entre as publicações que enfatizavam a fotografia documental (ou seja, que se relaciona com a realidade a partir de uma intencionalidade comprovatória, de testemunho e autoridade em relação ao que aconteceu) e a fotografia expressão (que possibilita outras formas do discurso imagético ao deslocar a fotografia de seu caráter utilitário em direção ao seu uso interpretativo). Há, portanto, uma ruptura com certos padrões ligados à objetividade jornalística e a busca por uma imagem em que a subjetividade, a sensorialidade e a leitura pessoal de um fato emerjam para o primeiro plano. Em geral, a revista Realidade privilegiava "fotógrafos que, ao desenvolverem suas pautas, não o fizeram presos à intenção de gerar uma simples prova visual dos fatos, eliminando possíveis dúvidas do leitor". Assim, “a intenção deles foi, realmente, imprimir uma interpretação particular da realidade, fazendo uso de uma linguagem pessoal" (LEITE, 2015, p. 9).

As estratégias de convocação para o consumo presentes nas capas de Realidade também se articulam a partir desse pressuposto, em uma abordagem bastante diferente daquela articulada no período anterior. Uma das características centrais das capas de revista dos anos 1940 e 1950 era o uso do star system da época (e, muito especialmente, das atrizes hollywoodianas) para a composição das capas de revista - predicado que pode ser observado nas principais publicações semanais da época como $O$ Cruzeiro e Revista da Semana.

No ano de 1958, por exemplo, das capas da Revista da Semana, 74,5\% possuíam apenas mulheres na capa, $10 \%$ apenas homens e $8 \%$ homens e mulheres (os demais 7,5\% não possuíam pessoas na capa, apenas paisagens naturais). Os personagens eram compostos majoritariamente por artistas (atores, modelos e cantores), sendo que poucas edições remetem a acontecimentos quentes - como, por exemplo, a foto de um foguete que representa a corrida espacial norte americana, a cobertura da Copa do Mundo ou a morte do papa Pio XII. Assim sendo, $94 \%$ das personalidades podiam ser identificadas pelo nome (apenas $6 \%$ não o são). 
No mesmo período, O Cruzeiro irá adotar estratégias bem semelhantes a essa. Tomando-se como referência o ano de 1958, nota-se também uma forte presença do star system feminino nas capas: $86 \%$ delas são compostas unicamente por mulheres, $6 \%$ unicamente por homens e $6 \%$ por homens e mulheres. Das capas com pessoas, $96 \%$ delas são compostas por celebridades que podem ser identificadas pelo nome (em detrimento de personagens que representam instâncias ou processos sociais) e em $82 \%$ dos casos elas aparecem sozinhas (conotando a valorização do indivíduo em detrimento de suas relações pessoais). Para Mauad (2005), grande parte das imagens de $O$ Cruzeiro era marcada pela "sexualização do espaço figurativo, com a escolha da mulher como objeto central na maioria das fotos".

Realidade adota estratégias composicionais diferentes para as suas capas. Do ponto de vista temático, destaca-se em Realidade a variedade de temas presentes nas capas. Em 1966, primeiro ano da publicação de Realidade, por exemplo, as capas que traziam temáticas relacionadas a comportamentos sociais perfazem $33 \%$ das capas; temas de cultura ocuparam $33 \%$ e esportes 22\%. As celebridades perfizeram apenas 12\% das capas. Em 1967, comportamento ocupa $83 \%$ das capas, seguido por política, em 17\% delas. Mesmo nas capas que continham personalidades famosas, contudo, os modos de articulação das técnicas de composição e das estratégias de convocação eram bastante distintos daqueles utilizados no período anterior, conforme detalharemos a seguir.

O lançamento da revista Realidade pode ser inserido em um contexto mais geral, que abarcava outras publicações da mesma época, que dizia respeito à busca por novos modos de se fazer reportagem. A criação da Realidade foi debitária de toda uma cena cultual formada nos anos anteriores por publicações alternativas consumidas pela classe média intelectualizada. A revista - assim como outros veículos noticiosos como Correio da Manhã, Zero Hora, Jornal da Tarde e Folha da Tarde - incorporou esse clima de denúncia, de contestação e de oposição já fomentado pelas experiências em jornalismo alternativo e que foram incorporadas por veículos da grande imprensa (KUCINSKI, 1991). Nesse movimento, “é possível identificar um discurso libertário e contestador", ligados a uma imprensa engajada e que buscava um outro tipo de visada em relação aos problemas sociais. Para Faro (1999, p. 6), Realidade foi criada para um público de classe média e soube se manter dentro das fronteiras que eram tidas como aceitáveis pelo público médio geral, não muito simpático aos movimentos da esquerda. Nesse sentido, ela abarcou, em um mesmo movimento, o discurso transgressor dos anos 60 com a adoção dos "valores burgueses conservadores, a ordem do 
Estado e a ordem da estrutura social", o que explicaria em grande medida o sucesso obtido pela publicação.

No que diz respeito às imagens de capa, não apenas as celebridades deixaram de ser prioritariamente representadas, como a maior parte das imagens passa a remeter não a pessoas identificadas pelo nome, mas sim, a instâncias e/ou processos sociais. Nesse sentido, em 1966, por exemplo, as capas sem pessoas (compostas por figuras abstratas ou por objetos) perfizeram $45 \%$ das edições. Mesmo nas capas com pessoas retratadas (sendo $11 \%$ delas com mulheres, $22 \%$ com homens e $22 \%$ com homens e mulheres), apenas em $33 \%$ delas era possível identificar o personagem retratado pelo nome - no restante, eles performavam figurativizações de processos, instâncias ou atores sociais.

Em 1967, a mesma tendência é mantida. Embora as capas com figuras abstratas ou objetos perfaçam $25 \%$ das edições, nas capas que possuem pessoas (sendo $25 \%$ com mulheres; $50 \%$ com homens; e $25 \%$ com homens e mulheres), em apenas $10 \%$ delas essas personalidades podem ser identificadas pelo nome. Nas demais, elas são representativas de processos sociais.

Os processos sociais, portanto, se destacam como o grande personagem a ser retratado nas capas da revista Realidade. Tais expedientes técnicos, portanto, encerram outros modos de convocação pela imagem nas capas de Realidade, pouco usuais nas revistas até então, conforme discutiremos a seguir.

\section{A JUSTAPOSIÇÃO COMO TÉCNICA de COMPOSIÇÃO: A ÊNFASE NO PROCESSO COMO MECANISMO CONVOCACIONAL EM REALIDADE}

\subsection{A justaposição como mecanismo de produção de sentido:}

Toda imagem sempre remete a algo além dela própria. É nesse sentido que Boehm (2015, p. 25) coloca que "de fato, a maior parte das imagens, as imagens de uso, cotidianas e típicas, visam ser lidas para além da imagem". Isso significa que o seu estatuto iconológico está sempre presente, pautando o jogo das conotações instaladas nos processos de produção de sentido pela imagem, de forma que "pouco importa, aliás, se se trata de fotografias banais ou de pinturas ditas exigentes: a imagem representa um caso de figura cujo espaço de significação precede, a título de pré-texto, toda significação”. Há na imagem, portanto, a articulação interna de significações externas. É por isso que uma imagem é sempre menos do que ela representa - na medida em que depende dessas significações externas - e mais que 
seu objeto físico - posto que sua apresentação sempre encerra certa opacidade (ALLOA, 2015, p. 12).

É também nesse sentido que Samain (2012, p. 22) coloca que há uma relação privilegiada entre aquilo que a imagem mostra e o que ela dá a pensar, na medida em que ela realiza um trabalho "ao se associar, notadamente, a outras imagens (visíveis/exteriores; mentais/interiores) e a outras memórias" e arcabouços culturais. As imagens são, portanto, "formas que, entre si, se comunicam e dialogam".

As estratégias mais comumente utilizadas nas capas da Revista da Semana e de $O$ Cruzeiro para fazer a imagem significar e remeter a algo externo a ela própria estava bastante relacionada à mostração de figuras exemplares (algumas vezes, políticas, mas, mais comumente, vinculadas às celebridades hollywoodianas) que, no plano conotativo, remetiam a certos modos de vida validados e convocavam ao consumo ao efetuar a partilha entre os valores que deveriam ser celebrados e aqueles que estavam fora de um campo autenticado de visibilidade. O projeto afetivo-editorial dessas publicações, embora tenham variado bastante ao longo do tempo, estruturou frequentemente as suas estratégias de convocação para o consumo na personificação de valores a partir dessas figuras exemplares.

As celebridades, para Serpa (2006), não eram mais do que uma estratégia de convocação para o consumo. Para a autora, $O$ Cruzeiro mediava uma "realidade fantasiada a partir de informações vindas em abundância dos estúdios da capital do cinema mundial, que estimulavam, as moças e senhoras a se espelharem nas estrelas de Hollywood" que, por sua vez "usavam cosméticos, belas roupas, tinham novas ideias e conquistavam a fama e o prestígio social. Mas foi sobretudo através da propaganda de produtos que enalteciam a beleza e que reforçavam a ideia de uma nova mulher, agora mais consumista, que a revista vendia o sonho de mudanças" (SERPA, 2006, s.p.).

Em um primeiro momento, havia a predominância de celebridades norte-americanas e europeias. A partir de 1941, é possível observar a inserção de algumas artistas brasileiras. A temática da celebridade era, de fato, importante para a revista, de forma que ela chegava a representar, em média, mais de dois terços das capas do período.

A evocação às celebridades, como coloca Adamatti (2008, p. 70), não é um mecanismo de convocação que simplesmente faz com que os leitores queiram consumir produtos de uma maneira irracional. O mecanismo é bem mais sutil e diz respeito projeções de imaginários socialmente construídos. As atrizes medeiam "parâmetros comportamentais, lembrando que elas são mensageiras do mito da felicidade e também de parte dos ideais da 
sociedade". Sobre isso, é interessante lembrar, ainda, que estamos em um período anterior ao surgimento das celebridades rebeldes: até os anos 50, as estrelas representavam valores bons e positivos que se objetivavam nas notícias sobre suas vidas pessoais. "Assim, a partir de detalhes, como saber o perfume preferido da estrela, o seu novo penteado, ou a forma de lidar com a tríade carreira/casamento/filhos, o leitor se vê imbuído de informações úteis para lidar com o seu mundo, a partir de parâmetros de comportamento dos mitos", ou seja, "daqueles que possuem talento, carreira, dinheiro e principalmente amor conjugal".

No mercado editorial brasileiro da época, é bastante mais comum que esse tipo de direcionamento afetivo-editorial - a partir do qual a celebridade é construída como um modelo de conduta - se direcione especialmente às mulheres (tanto a partir do elogio do modo de vida das celebridades quanto a partir de censuras feitas aos seus comportamentos desviantes). Normalmente, tais construções derivavam de uma visão de mundo bastante conservadora que estabelece um papel submisso e moralista às ações femininas. E é nesse ponto que o conservadorismo e o consumo são urdidos. Tal como apontado por Adamatti (2008, p. 77), no mercado editorial de revistas brasileiro "havia dois tipos de representação paralela da mulher nas revistas": "no texto, havia a vinculação como esposa e mãe. Nas imagens, como consumidora para vender os produtos em voga". Além da propaganda direta dos produtos, existia nessas revistas um mecanismo mais sutil de convocação ao consumo feita a partir do material jornalístico, tanto a partir do comentário sobre os produtos preferidos das estrelas e dos seus hábitos de vida, quanto a partir de dicas de consumo (de moda, maquiagem, serviços e comportamentos). Assim, "os produtos de consumo são instigados no estágio dos temas imaginários de ordem prática, onde se exerce a pressão da indústria" (ADAMATTI, 2008, p. 78).

Até a década de 1960, a maior parte das estratégias convocacionais das revistas brasileiras estavam articulados em torno de seu potencial dêitico que se coadunava a uma competência metafórica. E isso no sentido de que, por um lado, as imagens de capa fundavam e estruturavam um campo mostrativo da linguagem, ao exibir as personalidades que supostamente deveriam ser reconhecidas e estimadas, por outro, tais personalidades estavam impregnadas de valores associados que produziam sentidos figurados a partir de associações metafóricas implícitas.

As capas de Realidade não se atêm a esses princípios, de forma que é possível observar, ali, um desenvolvimento da questão da mostração como tema em direção à mostração como princípio operador (BOEHM, 2015, p. 34). Os dois conjuntos de estratégias 
convocacionais articulam regimes diferentes entre o visível e o dizível, de forma que as catarses afetivas se estruturam de maneiras distintas nas estratégias de convocação para o consumo.

As estratégias de convocação nas capas de Realidade estão articuladas a partir de um mecanismo de produção de sentido pela imagem que combina: (1) uma técnica composicional específica (a saber, a justaposição), elaborada a partir de um (2) acordo profissional específico sobre as novas formas de jornalismo que emergem a partir da década de 1960 (a partir de reposicionamentos da relação entre fato narrado e personagem) que se materializam no conteúdo da imagem e que engendram (3) um outro modo de construção discursiva do lugar do leitor e sua consequente interpelação em termos convocacionais (que interpela o sujeito a partir do explicitamento do processo de significação da imagem e da destituição da primeira pessoa como articuladora do fato na narrativa). Esses termos serão detalhados a seguir.

Desde a primeira capa da revista, a da famosa foto de Pelé com um chapéu da guarda real inglesa, publicada em abril de 1966, a combinação dessas três estratégias composicionais pode ser notada.
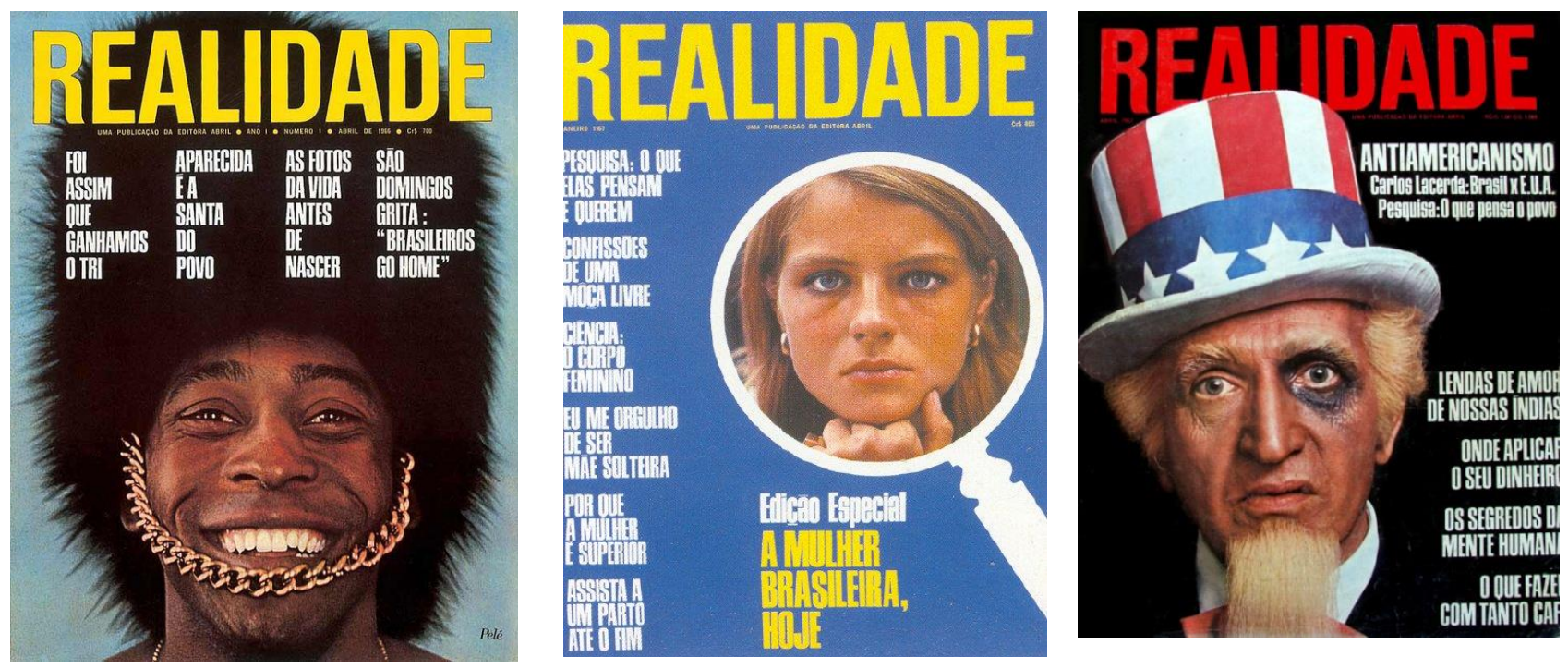

Figura 1 - Capas das edições de Abril de 1966, Janeiro de 1967 e Abril de 1967, respectivamente

Em primeiro lugar, destaca-se que, embora frequentemente Realidade também se valesse da representação de celebridades em suas capas, elas não eram apresentadas a partir de uma simples mostração. O uso da técnica da justaposição sobressai como eixo articulador da composição imagética das capas de Realidade, sejam elas com celebridades ou não. A 
justaposição é uma técnica de composição caracterizada pela junção de duas figuras que pertencem, normalmente, a universos semânticos distintos, de forma que a junção das duas estabelece um terceiro campo semântico a ser evocado na interpretação. Ela opera uma montagem - que pode se dar durante a própria feitura da fotografia ou ser acrescentada posteriormente na edição - entre figuras de naturezas diferentes. No caso da revista Realidade, normalmente, uma das imagens pode ser considerada como a principal - no sentido de que ela pauta o tema que está sendo veiculado como a "notícia mais importante" na capa. A outra imagem faz as vezes de adjetivação da primeira, na medida em que caracteriza ou modifica a leitura simples dessa primeira imagem e afeta de forma decisiva a leitura global da imagem.

Na capa com a imagem de Pelé, por exemplo, a justaposição é articulada a partir da junção do ídolo do esporte (como personagem principal da história contada) e o chapéu da guarda inglesa, como imagem secundária, que completa a justaposição e qualifica a história contada; no caso da capa de janeiro de 1967, a justaposição é composta pela mulher (imagem primária) e a lupa, como modificadora da primeira; na capa do Tio Sam, a imagem central é composta pelo ícone norte-americano e a adjetivadora pela justaposição do soco no olho.

Há, portanto, nessas justaposições, a inserção de um material significante em outro. A trucagem de figuras feita na justaposição "afeta a grafismo da obra e esse grafismo, por sua vez, modifica a realidade dos fragmentos colados, absorvendo-os na linguagem metafórica da descrição visual”. O fragmento colado, assim, adquire uma capacidade de significação para além daquilo que ele é, de forma que "o pedaço de colagem afirma sua existência enquanto objeto real e, ao mesmo tempo, sua capacidade de representar, significar, substituir algo mais" (KRAUSS, 2013, p. 165).

A justaposição, portanto, como mecanismo de composição principal que estrutura a capa da revista, opera a partir da junção de elementos pertencentes a campos semânticos distintos, em uma estrutura única que convida o leitor ao deciframento de um terceiro sentido implicado a partir dessa junção.

\subsection{A justaposição do ponto de vista do conteúdo:}

Há, no entanto, uma outra questão que deve ser posta: em termos de conteúdo, as duas imagens que formavam a justaposição das capas de Realidade não eram aleatórias. Elas sempre diziam respeito a dois campos semânticos bem específicos (a saber, um deles do personagem e o outro referente ao social, conforme detalharemos a seguir) e que estavam 
relacionados a acordos profissionais específicos acerca do modo como o jornalismo passou a ser pensado a partir da década de 1960. Há, portanto, uma rearticulação da própria função do jornalismo que redefinem os parâmetros convocacionais de suas estratégias imagéticas.

As estratégias de convocação da Revista da Semana e de O Cruzeiro estavam articuladas em torno da ideia de que os acontecimentos e fatos referem-se, primordialmente, a um sujeito (designado por um nome próprio). A partir da década de 1960 emerge uma noção que revoga "o primado dos acontecimentos e dos nomes próprios em benefício (...) da vida dos anônimos" (RANCIÈRE, 2014, p. 2). A imagem acompanha um movimento que já se dava na narrativa jornalística escrita, em que a história escrita em primeira pessoa perde espaço e cede espaço a personagens mais amplos.

Os sujeitos da escrita jornalística mudam de forma acentuada a partir de meados da década de 1950, de maneira que se prefere falar da vida das mulheres, do que da vida de uma mulher em específico. A descrição da vida doméstica de uma celebridade específica, por exemplo, cede espaço a um retrato mais amplo das brasileiras hoje. O modo de convocação é redirecionado para os grandes fenômenos sociais, aqueles "que não se atribuem mais a um sujeito particular, mas que se observam em sua repetição, se deixam classificar de acordo com suas propriedades e se correlacionam com outros fatos do mesmo tipo ou com outros tipos de fatos" (RANCIÈRE, 2014, p. 3).

Tal redirecionamento, contudo, não se esgota nesse ponto, já que o personagem individual não é totalmente abandonado na narrativa (muito embora ele seja engendrado em outros termos). Tal como formulado por Rancière $(2014$, p. 3), "nem por isso deixaremos de enfrentar o salto no vazio (...): é preciso nomear sujeitos, é preciso atribuir-lhes estados, feições, acontecimentos". Apesar de um redirecionamento das pautas para aspectos sociais brasileiros mais amplos, o jornalismo não se desfez completamente da primazia do personagem, embora tenha-o incorporado de uma maneira diferente, tanto na narrativa textual quanto em suas esquematizações imagéticas. Há, sim, um reengendramento da articulação entre os nomes e os acontecimentos, de forma que é reconciliado um interesse jornalístico novo (as histórias sociais de grande espectro, não relacionadas a um personagem específico, mas a camadas sociais mais amplas) e um velho modo de contar histórias (que não larga de todo a personalização dos acontecimentos e ainda usa uma figura individual para exemplificar esses processos sociais mais amplos).

Há, a partir da década de 1960, uma “elaboração poética do objeto" (RANCIÈRE, 2014, p. 10) jornalístico nova que conjuga a figura particular (o personagem) com um 
movimento social de amplo espectro. São esses os dois termos que regem as justaposições implicadas nas capas da revista Realidade, de forma que sempre os dois elementos considerados dizem respeito a esses dois eixos. O primeiro elemento corresponde, assim, ao personagem e o segundo diz respeito ao enquadramento desse personagem em um movimento social mais amplo.

Do ponto de vista temático, portanto, o uso da justaposição como técnica composicional atende a esses rearranjos do jornalismo em geral, que assume uma nova forma de narrar o fato. A justaposição, nesses termos, é a expressão imagética de um movimento que já se articulava no texto (a partir de outros mecanismos semânticos e narrativos) desde ao menos meados da década de 1950.

\subsection{A justaposição do ponto de vista da construção de um lugar de leitor:}

A destituição da primeira pessoa do relato engendra, ainda, um modo distinto de construção discursiva do lugar do leitor, de forma que a sua interpelação em termos convocacionais se dá a partir do explicitamento do processo na construção da imagem a partir da justaposição como técnica composicional estruturante.

O uso da justaposição como técnica de composição evoca um campo convocacional diferente daquele estruturado em torno de potencial dêitico e metafórico da linguagem imagética (como presente nas capas de O Cruzeiro e Revista da Semana). E isso porque há uma outra lógica de mostração implicada na evocação desse tipo de técnica de composição. Na justaposição, "a lógica da mostração só pode ser processual”, de forma que a imagem deve ser concebida como "uma equação energética". Ou, em outros termos, "o que mostra - a imagem, em sua ocorrência - nos mostra como alguma coisa se mostra. E, ao nos dar a perceber, a imagem gera um sentido" (BOEHM, 2015, p. 38). Em outros termos, o leitor é convocado a participar da resolução de uma espécie de enigma para a atribuição de sentidos e, ao fazê-lo, a própria imagem se apresenta do ponto de vista de um processo a ser percorrido aquele ligado às transferências de sentido em operação para a composição da imagem.

Isso porque, na justaposição, o que "constitui a imagem é a operação que transforma uma corporeidade em outra" (RANCIÈRE, 2015b, p. 200), a partir da junção de elementos que pertencem a campos semânticos distintos. Há na lógica composicional da justaposição sempre a pressuposição do desvendamento de um engodo: aquele da própria ilusão referencial da fotografia. Tal técnica de composição "revela a natureza puramente convencional da marca gráfica, graças a um sobrelanço no contraste ontológico", ao explicitar para o espectador a 
ilusão referencial da expressão fotográfica. A justaposição, ao associar dois elementos que não pertencem necessariamente a uma mesma ordem, “chama a atenção para essa qualidade de ausência, torna a própria ausência presente, por assim dizer, e revela a verdadeira natureza da representação, que não passa de aparência, redução, substituta, signo” (KRAUSS, 2013, p. 167).

A justaposição age, assim, contra toda pretensão de uma imagem autorreferente, autônoma e total, na medida em que opera um questionamento do estatuto indiciário da fotografia a partir de um ponto de vista metafórico: trata-se de um modo de mobilizar, na própria composição, a noção de uma realidade percebida como arbitrária, "que necessariamente obriga toda representação a não ser mais que uma coleção de fragmentos". E, assim, "no próprio centro de seu poder de representação reside essa mensagem da ausência (do real), que é a primeira condição de qualquer representação” (KRAUSS, 2013, p. 168). Na justaposição, portanto, “a imagem não se identifica com o visível e os seus poderes de fala são aqueles de suas condensações e deslocamentos, que fazem ver uma coisa em outra ou por uma outra" (RANCIÈRE, 2015b, p. 193).

A linguagem imagética, nesse sentido, cede o seu potencial dêitico para a valorização de seu estatuto processual, ao escancarar para o leitor a construção de sentido enquanto um processo.

A trucagem, nesse sentido, é um mecanismo convocacional que impõem um pensamento "que forma, formata, põe em forma" (SAMAIN, 2012, p. 24). Ela põe em jogo um processo que traspõe a imagem para além dos objetos representados isoladamente e, ao fazê-lo, torna a imagem "o lugar de um processo vivo", participante de "um sistema de pensamento".

Assim, podemos dizer que a imagem é pensante (SAMAIN, 2012, p. 31) nas capas da revista Realidade. Mais do que isso, elas convidam o leitor a participar do processo justamente ao mostrar-se enquanto tal. O mecanismo de convocação se dá, então, a partir das imagens cruzadas, que "por pertencerem a um sistema, participam não apenas de um tempo e de um contexto singulares, mas sobremaneira de um sistema de pensamentos" (SAMAIN, 2012, p. 32).

Tal estratégia convocacional, tal como já pontuado por Rancière (2015a, p. 28) impõe uma guinada da ideia de que a imagem deve ser lida a partir do deciframento de seus significados misteriosos articulados, mas sim, "contrapõe-lhe uma nova hermenêutica que relaciona a imagem não a um sentido oculto, mas às condições de sua produção". É 
justamente ao explicitar as condições de sua produção que a justaposição utilizada na revista Realidade convida o leitor a participar da produção de sentido, não como algo imposto, mas como um desafio ao olhar.

Tais injunções convocacionais, obviamente, não são uma invenção de Realidade. “Trata-se propriamente de uma posição no interior do sistema de possíveis definido por uma determinada ideia” de imagem e de jornalismo (RANCIÈREa, 2015, p. 33). Para Rancière (2015a, p. 38) trata-se da emergência de um registro estético em que tudo na imagem fala. "A casa ou o esgoto falam, trazem consigo rastros do verdadeiro, como farão o sonho ou o ato falho - mas também a mercadoria marxiana -, desde que sejam primeiro transformados em elementos de uma mitologia ou de uma fantasmagoria”. Trata-se de fazer falar para além do fato, para além da mostração imediata, a partir de um trabalho onde a significação do fato é dado a partir de um trabalho de reescrita dos fatos.

A imagem convoca, em Realidade, portanto, não a partir da articulação aspiracional de um leitor imaginado (tal como em revistas do período anterior); mas sim, a partir da estruturação de um leitor modelo que é pensado como um ator na produção de sentido de suas capas, que é chamado a fazer parte do processo de composição de sentidos a partir de um trabalho de deciframento e decodificação dos acontecimentos apresentados pela publicação.

\section{CONSIDERAÇÕES FINAIS}

A partir do esmiuçamento dos processos de produção de sentido implicados na justaposição enquanto técnica composicional e suas implicações em termos de estratégias composicionais, é possível retomar a pergunta que motivou a presente investigação: o que, afinal, desejam as capas da revista Realidade?

Uma das premissas do fotojornalismo, ao menos do modo como ele vem sendo praticado desde a década de 1950, é o fato de que as imagens constituem um bem comum. Ao menos em seu caráter ethópico e deontológico, portanto, a função da imprensa seria restituir à sociedade as imagens que lhe é de direito, a despeito das instituições e dos jogos de poder específicos. Para Didi-Huberman (2015, p. 212), é por isso que tal restituição não se dá sem efeito transgressor, no sentido de que a imprensa restitui as imagens para o livre uso. As imagens, assim, não devem ser entendidas "como lugares-comuns - que suas remontagens desmontam ou constroem - mas como o lugar do comum" (DIDI-HUBERMAN, 2015, p. 223). 
Se retomarmos os pressupostos de Mitchell (2015) de que toda imagem deseja estruturar um apelo para que seus leitores a ouçam a partir da estruturação de mecanismos convocacionais, é possível dizer que existem dois tipos de restituição diferentes implicados nos dois períodos estudados. Quando pensamos nas estratégias convocacionais pressupostas na Revista da Semana e em O Cruzeiro, trata-se de uma ideia de restituição a partir da qual "um objeto do corpo privado (o rosto daquele cuja imagem é fabricada) retorna à esfera do direito público" (DIDI-HUBERMAN, 2015, p. 206). A convocação pela imagem se estrutura, assim, por seu potencial dêitico - o de nomear uma pessoa ou situação - associado a um potencial metafórico que se coloca nas pressuposições aspiracionais de um leitor modelo. Às imagens jornalísticas de capa, cabia o desejo de restituir os acontecimentos ao mundo (mesmo que isso se estruture mesmo como desejo imaginário e não como efetividade).

Não é o mesmo mecanismo que opera nas capas do jornalismo noticioso pós-década de 1960. O gesto de restituição de Realidade está vinculado à ideia de apropriação, ou seja, de um modo em que restituir signifique anexar, ou seja, "possuir, segundo o antigo valor do manicipium romano, como quando se compra alguma coisa - ou alguém - para dele dispor a sua maneira, segundo seu direito privado". No caso do fotojornalismo, "se dando ao direito de recontar uma história” (DIDI-HUBERMAN, 2015, p. 208), de tornar visíveis certos aspectos do enredo a partir de uma ótica de reinterpretação.

As imagens de capa de Realidade operam por remontagens interpostas que faz um novo uso delas, de forma a extrair a metáfora moral de um acontecimento por meio dessa mesma montagem. A imagem, nesse sentido, não é meramente contemplativa, mas sim, processual, uma vez que solicita uma posição outra por parte do sujeito espectador ao propor um novo jogo entre as formas tradicionalmente expostas pelo fotojornalismo. A demanda por uma outra posição-sujeito do espectador para um outro tipo de experiência, nesse sentido, se processa porque tais imagens decompostas tem uma proposta de problematização dos fatos a partir da decomposição das figuras. O gesto de restituição posto em operação pelas imagens de Realidade, portanto, a partir do uso da justaposição como técnica composicional estruturante, se funda no jogo com as imagens e no convite ao leitor para participar do processo de remontagem do mundo.

O que desejam então as imagens da revista Realidade? Ao se estruturar um mecanismo de sentido a partir do qual a justaposição é a técnica composicional estruturante e funda um jogo entre imagens de campos semânticos diferentes e um convite ao leitor para participar do processo de remontagem do mundo, as imagens de capa de Realidade conjuram 
um tipo de jornalismo que se coloca no lugar de interpretador legítimo dos fatos do cotidiano - a ponto de poder remonta-lo. Trata-se da materialização imagética de uma reestruturação jornalística mais ampla, que diz respeito à vinculação da revista Realidade a um projeto de jornalismo que recebeu a alcunha de interpretativo. Se, do ponto de vista textual, isso se materializa em códigos de narração específicos, do ponto de vista imagético, a justaposição se apresenta como elemento central de convocação. A imagem, portanto, deseja tanto convencer o leitor que ela pode, inclusive, justapor os elementos do mundo em favor de sua fábula moral específica.

\section{REFERÊNCIAS}

ADAMATTI, Margarida Maria. A crítica cinematográfica e o star system nas revistas de fãs: A Cena Muda e Cinelândia (1952-1955). Dissertação apresentada ao Programa de Pós-graduação em Ciências da Comunicação da Universidade de São Paulo. São Paulo: ECA-USP, 2008.

AGAMBEN, Giorgio. Profanações. São Paulo: Boitempo, 2007.

ALLOA, Emmanuel. "Entre a transparência e a opacidade: o que a imagem dá a pensar". In ALLOA, Emmanuel (org.). Pensar a Imagem. Belo Horizonte: Autêntica, 2015.

BOEHM, Gottfried. "Aquilo que se mostra: sobre a diferença icônica". In ALLOA, Emmanuel (org.). Pensar a Imagem. Belo Horizonte: Autêntica, 2015.

CERTEAU, Michel de. A Escrita da História. Rio de Janeiro: Forense Universitária, 2008.

DIDI-HUBERMAN, Georges. "Devolver uma imagem". In ALLOA, Emmanuel (org.). Pensar a Imagem. Belo Horizonte: Autêntica, 2015.

FARO, José Salvador. Revista Realidade: tempo da reportagem na imprensa brasileira (19661968). Canoas: Ulbra, 1999.

KRAUSS, R. O Fotográfico. Barcelona: Editorial Gustavo Gili, 2013.

KUCINSKI, Bernardo. Jornalistas e Revolucionários: nos tempos da imprensa alternativa. São Paulo: Scritta Editorial, 1991.

LEITE, Marcelo Eduardo. "Desconstruindo fronteiras: alguns apontamentos sobre a revista Realidade". Anais do $\mathbf{1 0}^{\mathbf{0}}$ Encontro da ALCAR. Porto Alegre: ALCAR, 2015.

MAGAlhães, Angela, PEREGRINO, Nadja Fonseca. Fotografia no Brasil - Um olhar das origens ao contemporâneo. Rio de Janeiro: FUNARTE, 2004.

MAUAD, Ana Maria. "Na mira do olhar: um exercício de análise da fotografia nas revistas ilustradas cariocas, na primeira metade do século XX". Anais do museu paulista, v. 13, n. 1, junho de 2005.

MITCHELL, W.J.T. “O que as imagens realmente querem?”. In ALLOA, Emmanuel (org.). Pensar a Imagem. Belo Horizonte: Autêntica, 2015. 
NANCY, Jean-Luc. "Imagem, mímesis e méthexis". In ALLOA, Emmanuel (org.). Pensar a Imagem. Belo Horizonte: Autêntica, 2015.

RANCIÉRE, Jacques. Os nomes da história. São Paulo: Editora da UNESP, 2014.

RANCIÈRE, Jacques. O inconsciente estético. São Paulo: Editora 34, 2015 a.

RANCIÈRE, Jacques. “As imagens querem realmente viver?”. In ALLOA, Emmanuel (org.). Pensar a Imagem. Belo Horizonte: Autêntica, 2015 b.

SAMAIN, Etienne. "As imagens não são bolas de sinuca". In SAMAIN, Etienne (org.). Como pensam as imagens. Campinas: Editora da Unicamp, 2012.

SERPA, Leoní. “A mulher na revista O Cruzeiro (1928-1945)”. PJ:BR, v. 1, n. 07, Julho-Dezembro de 2006.

Original recebido em: 27 de junho de 2017

Aceito para publicação em: 07 de dezembro de 2017

Eliza Bachega Casadei

Doutora em Ciências da Comunicação pela Escola de Comunicações e Artes da Universidade de São Paulo (ECA-USP). Professora titular do Programa de Pós-graduação em Comunicação e Práticas de Consumo da Escola Superior de Propaganda e Marketing (PPGCOM-ESPM)

Esta obra está licenciada sob uma Licença Creative Commons. 